\title{
12
}

\section{Temporary Futures, Permanent Constraints: Wellbeing of Pasifika Youth in Australia}

\author{
Lila Moosad
}

\section{Introduction}

Successive Australian prime ministers have invoked sentiments of 'we are family' when discussing the relationship between Australia and Aotearoa/ New Zealand. Most recently, it was former Prime Minister Malcolm Turnbull when he first met New Zealand Prime Minister Jacinda Arden in 2017 (McGowan 2017). These sentiments, however, are not borne by regulatory changes that target the entitlements that New Zealand residents who arrived prior to 2001 enjoyed in Australia; these changes deliberately and systematically disadvantage New Zealanders who have moved to Australia since February 2001. This chapter focuses on these changes and their effect on the lives of young Pasifika whose families moved to Australia in search of 'a better future for their kids', as one of the participants in this study stated. The young Pasifika women who were affected by these changes were in the final years of their high school-a critical point in their lives when they consider decisions about their study and employment pathways. As these Pasifika women soon realised, these options were hedged with limitations for them and other young New Zealand citizens who were affected by the post-2001 changes. I use the frame of wellbeing to show how these changes affect their futures in 
practical and immediate ways. The changes are also salient to a broader wellbeing narrative of belonging and citizenship that is used against Australia's ever-increasing category of temporary residents.

\section{Methodology}

This chapter is based on my ethnographic work and comprises the insights of the many young Pasifika women who I met during my fieldwork between September 2015 and April 2017. Many of them participated in various cultural and leadership projects that were initiated by the youth services at the Acacia council in Melbourne's west. The young women were part of a youth committee that I call Pasifika Voices. ${ }^{1}$ These projects were often in collaboration with local arts organisations and Pasifika community artists and mentors. The project dates were aligned with the school terms and ended in early December. December signalled the start of a busy month for the young people, with many returning to visit family in Aotearoa/New Zealand or Oceania. Others were kept busy with family commitments in the weeks leading up to Christmas and New Year's Day. We met in February in 2016 and 2017.

The young women ranged from 17 to 27 years in age and were born in Australia, New Zealand and Samoa. They were predominantly Tongan and Samoan, and some were of mixed Pasifika or non-Pasifika heritage. Most were at school or university; others were working or looking for work. During my fieldwork, some of the young women moved into work and tertiary study. The experiences of being Pasifika in Melbourne for these young women were shaped by their transnational experiences and their connections to their communities spread across New Zealand, Melbourne, Samoa and Tonga. While they identified as Pasifika in the context of council projects, they also identified as Tongan or Samoan in other settings, and as Australian, New Zealander and Oceania-born in yet other contexts. Their everyday lives around family, church, work, study and friendship networks varied as well. It was in these overlapping spaces that the contradictions and tensions that were inherent in the young women's wellbeing experiences became clearer. The strengths and

1 Names of participants, organisations and places have been de-identified. 
resources that these sites offered were also made visible. In this chapter, I specifically focus on young women whose families moved to Australia from New Zealand after 2001.

My ethnography also includes insights from other members of the Pasifika communities, some of whom were related to the young women in my study. I also spoke to representatives from the service agencies that were working with the young women or Pasifika youth generally. They included Pasifika and non-Pasifika artists, Pasifika researchers, community and religious leaders, social and youth workers and Victorian police force members.

In the following sections of this chapter, I discuss the implications of the changes that the Australian government implemented in 2001, drawing on my fieldwork and the theoretical framework of structural vulnerability. I also discuss the notion of wellbeing, as it relates to the immediate constraints of young people's lives and to the broader notions of citizenship and belonging in Australia.

\section{Changes to Visa Status}

Early in my fieldwork, I met Mele and Ema, who were part of the Pasifika Voices youth committee. Some months later, I met Amelia, who was a friend to many young women in the youth committee. Mele's family had moved from Aotearoa/New Zealand to Melbourne in 2008, and Ema's and Amelia's families had moved in 2015. Ema went straight into Year 12 in 2015, which is the final year of high school in Australia. Mele and Amelia completed high school in 2016. I am precise about their dates of arrival in Australia because the regulatory changes that the Australian government introduced in 2001 significantly constrained opportunities for them and the other Pasifika youth who arrived in Australia after 2001.

The 2001 changes were part of the amendments to Australia's Social Security Act 1991 and were in response to Australia's policy concerns about the increasing numbers of people who were 'born in third-world countries', even though arrivals from Aotearoa were New Zealand citizens and increasingly New Zealand-born (Hamer 2014, p. 110). These anxieties about the 'back door' migration from Aotearoa, which were a legacy of suspicion from the White Australia Policy days, do not reflect the reality of demographic changes in Aotearoa (Mares 2016). 
Under the 1973 Trans-Tasman Arrangement between Australia and Aotearoa, there was unrestricted movement between the two countries. Australian and New Zealand officials treated this Trans-Tasman movement into another country as a separate matter to the official migrant intake of their countries. It was an acknowledgement of historical connections and close bilateral ties. Over time, the original arrangement, whereby citizens from both countries could live and work indefinitely in one another's countries with unhampered passport and visa-free entry and all the benefits of permanent resident status, tightened. From 1981, New Zealand citizens were required to present a valid New Zealand passport; in 1986, children born to New Zealand citizens in Australia no longer had automatic citizenship rights; and, in 1994, the Special Category Visa (SCV) was created for New Zealand citizens. This SCV was envisaged as a temporary category, and this classification took on particular significance after the 2001 changes (McMillan 2017). By 2000, the qualifying period to access welfare benefits was extended from six months to two years. These benefits ceased after the 2001 regulatory changes. These welfare restrictions are in contrast to the treatment of Australians moving to New Zealand who automatically became permanent residents with access to welfare and citizenship eligibility after a qualifying period.

The 2001 amendments to Australia's Social Security Act 1991 have had negative effects on the New Zealand citizens who arrived in Australia after 2001. The new SCV subclass 444 would permit New Zealanders to live and work (and pay taxes) as indefinite and non-protected temporary residents, but without access to the public housing, student loans, disability, health, welfare services and special assistance offered in times of disasters that other permanent residents are entitled to. This visa is issued to New Zealand citizens at the time of entry and is valid for the length of their stay in Australia. A gap has now opened in the level of protection offered through public welfare and health services between the post-2001 arrivals that were issued with the 'non-protected' SCV and the 'protected' SCV holders (pre-2001 New Zealander residents). Unlike the former group, the latter group continues to be entitled to the same benefits as Australian citizens.

A pathway to permanent residency in Australia became available for New Zealand citizens in July 2017 (Mares 2016). However, this is a costly and protracted process that essentially amounts to providing payroll receipts that demonstrate taxable income of at least $A \$ 53,900$ in the previous five years, as well as to additional application processing costs. Another 
restriction is that this pathway is only available to New Zealanders who arrive before 19 February 2016 (McMillan 2017). A major reason that Australian permanent residency status and citizenship will remain unattainable for many families is the prevalence of Pasifika workers in low-skilled, casual and precarious work. It is unlikely that many of these workers will average an income in excess of $A \$ 53,000$ for each of the last five years, and, given the nature of the employment, it is difficult to collate the required documentation.

The people who are designated as 'temporary' residents by the Australian government pay taxes and contribute to the community in many other ways. The altered circumstances that this legal differentiation creates for this group exemplifies the 'dynamics of social exclusion and the limits placed on citizenship' (Quesada et al. 2011, p. 347). The treatment offered by the Australian Taxation Office for purposes of tax liability is consistent with that of a permanent resident; yet, citizens of New Zealand who arrived in Australia after 2001 have a status of 'temporary-ness' in regard to accessing Australian welfare services (Mares 2016). The inconsistencies in this regime are experienced as iniquitous and baffling due to the conveyed sense of movable parts in the regime and due to the seemingly opportunistic shifts of legal interpretation in the nation state's concept of belonging and citizenship. For example, New Zealanders with post2001 SCVs are denied the services that are provided under the National Disability Insurance Scheme because they are not considered Australian residents under the Social Security Act. Yet, they are obliged to pay levies through their taxable incomes towards the scheme because, under the Health Insurance Act 1973, they are defined as Australian residents (Mares 2016, p. 137).

The 2001 Social Security Act precludes Pasifika youth who fall into the nonprotected SCV category from several benefits that are available to those who have permanent residency. These include unemployment benefits, youth unemployment benefits, sole parent benefits, carer payment or allowance paid to carers who look after children or adults with a medical condition or disability, Austudy - which is paid to full-time studentsand Special Benefits (Walsh 2015, p. 679). Ema and Amelia felt pressured to quickly find any sort of work after finishing school, particularly since, unlike many of their peers, they could not claim unemployment benefits. Welfare experts consider the Special Benefit as 'the ultimate safety net in the Australian social security system' (Walsh 2015, p. 683); it is paid to people who are ineligible for all other benefits. There is concessionary 
access to unemployment, youth unemployment and sickness allowance (but only as a one-off payment) for a maximum period of six months for New Zealand citizens who have resided in Australia continuously for at least 10 years. Those who have arrived in recent years are excluded from accessing these benefits, whether they are transitioning from school to work like Ema and Amelia or whether they are in common situations of being retrenched from unstable employment.

Families with unprotected SCVs face added risks related to domestic instability since the 2001 changes to the regulations to remove emergency and public housing access. Under the conditions of their funding, agencies that are funded to provide settlement services for newly arrived migrant communities in Australia cannot work with New Zealand citizens. Youth workers outlined to me that because of the restrictive rules, Pasifika families with temporary visas who experience settlement issues have to be referred to agencies other than the specialist settlement ones. According to the youth workers, the 2001 policy change significantly affects New Zealand citizens in family violence situations who are unable to access housing, financial and legal assistance. They described several examples of New Zealand citizens in family violence situations who are unable to access such assistance in the way that newly arrived permanent residents would be able to. Women (who are predominantly the victims of domestic violence) are unable to return to New Zealand with their children without their partner's approval (Mares 2016) and they often end up remaining in their abusive environments. Non-protected SCV Pasifika youth in need of emergency housing are also not considered a priority group. Youth workers who work with these young Pasifika at risk of homelessness speak of the challenges of being able to secure housing support for them, as well as their reliance on non-government agencies to assist young people and their families who are New Zealand citizens.

Many Pasifika families become aware of these limitations and their consequences only after arriving in Australia. The technicalities of Australia's health, education, social security and immigration laws were not at the forefront of their minds when deciding to move countries. In any case, one's SCV status is recorded electronically rather than in his or her passport on arrival (Kearney 2012). Mele's mother was only vaguely aware of the restrictions, but she found that she needed to clarify its implications when Mele started thinking about studying at university. Similarly, Ema's and Amelia's parents only vaguely knew of the restrictions to their daughters' pursuit of further studies. The 10-year residency 
requirement attached to the major forms of tertiary education support that is provided through the Australian government excluded Ema, Amelia and Mele from government-supported university places and from accessing the student loans scheme.

Further confusion about what support they could expect also arose from the split jurisdictions for post-school education and training between state and federal governments. New Zealand citizens are eligible to enrol in Victorian state government-funded vocational training, but to access a university course (the federal jurisdiction), they are ineligible to apply for the deferred tuition loans under the Australian government's FEEHELP scheme. This means that to pursue degree studies, they must pay (prohibitive) upfront fees of up to $A \$ 10,000$ each year before they start to think about their living costs. Australian citizens, pre-2001 New Zealand citizens and post-2001 New Zealand citizens who have been here for 10 years are eligible for FEE-HELP, which means that they are not required to repay their accumulated tuition debt until their annual income has crossed a threshold of $A \$ 55,000$. Typically, this would be someone who has graduated into well-paid employment and who could afford to start paying the debt.

\section{Structural Vulnerability}

The concept of structural vulnerability, theorised by Seth Holmes (2011), James Quesada et al. (2011) and Philippe Bourgois et al. (2017), critically evaluates the health effect on communities and individuals given their situation within 'socio-economic, political, and cultural/normative hierarchies' - that is to say, hierarchies that are 'overlapping and mutually reinforcing' (Bourgois et al. 2017, p. 300). Quesada et al. (2011) have drawn on the notion of structural violence, which is theorised often in post-crisis neo-colonial societies by anthropologist and physician Paul Farmer (2003), to develop the more nuanced and diffused concept of structural vulnerability. Structural vulnerability removes suggestions of overt violence (the notion of living in a 'failed state'), which facilitates the application of the concept to include a greater range of socioeconomic circumstances, such as urban communities experiencing disadvantages in the rich world. Quesada et al. (2011, p. 341) suggested that structural vulnerability should be viewed as a 'positionality', whereby 'the vulnerability of an individual is produced by her location in a hierarchical social order and its diverse networks of power relationships and effects'. Much of 
the work on structural vulnerability has been with Latino agricultural workers in the United States, but it is equally applicable to marginalised populations. It analyses and critiques a matrix of factors that work to create conditions of vulnerability for these migrants' health and wellbeing. Structural vulnerability in these communities is generated through a combination that could include racialised stereotyping, social exclusion, immigration status, labour market position, the practical implications of trade agreements between the United States and Mexico, working conditions and political discourses of 'illegal' migrants. The resulting understandings of structural vulnerability, Quesada et al. (2011) argued, have to be incorporated in clinical encounters with vulnerable groups like Latino migrant workers and other excluded minorities.

I use the concept of structural vulnerability to analyse the forces that constrain the lives and wellbeing opportunities of the young Pasifika women as a direct result of the 2001 regulatory changes. I suggest that wellbeing needs to be viewed as a relational and unfolding process. This approach identifies the constraining forces as continuously presenting impediments. It underscores that the social and regulatory limitations that are placed on the young women and their families must be understood as dynamic processes that are continuously recreating the conditions of vulnerability.

\section{Wellbeing}

The focus of much of the nascent health literature on Pasifika communities in Australia has been on individual markers of ill health, such as obesity, diabetes, renal disease and cardiovascular and respiratory conditions; it has also covered the experiences of adult (Polynesian) Pasifika in the Australian health system (McCarthy et al. 2010; Rodriguez 2013; Rodriguez \& George 2014). The common analytical approach to the Pasifika health issues of these studies is based on a biomedical framework. At one level, the stories that the young women told me of family members with medical conditions like diabetes and cardiovascular disease and of the premature deaths of family members underlined the credibility of this approach. However, a broader concept of wellbeing for young Pasifika women is rarely a feature in these medical and epidemiological studies - one reason presumably being that they are a small subgroup of the population. Along with these medical perspectives, other necessary fields of analysis can be opened through ethnographic and structural 
approaches. Wellbeing is a contested and ambiguous concept and it is significant that, to capture this notion, rich empirical studies draw on multiple disciplinary and theoretical approaches.

Some biomedical and popular approaches to wellbeing have focused on measuring wellbeing by using a set of categories, and they have assumed universalised experiences. These interpretations have their origins in the Global North (Atkinson 2013; White 2016) and are generally written from the perspectives of those 'already in a position of relative material advantage' (White 2016, p. 5). Generally, these components have focused on the individual as the primary acquirer of wellbeing. This individualised approach to wellbeing, Sarah Atkinson (2013, p. 141) argued, can then be extended to attribute the 'failure of wellbeing' to a result of 'failure of responsible citizenship'. These references to the individual are in parallel to the neoliberal discourse that assigns responsibility elsewhere from broader political, social and economic policies that affect wellbeing.

In the last decade, scholars have turned away from the initial focus on quantitative methods to explore other dimensions of wellbeing through qualitative, mixed methods and careful ethnographic work. As a counter argument to the earlier emphasis on capturing wellbeing through categories, measurements and rankings of many educational, psychological and medical disciplinary approaches, social scientists from anthropology, sociology and geography have reframed the ways of conceptualising wellbeing. These studies draw attention to the complex and relational aspects of wellbeing, shift the focus to the 'socially and culturally constructed' aspects of wellbeing (White 2016, p. 5) and address where and how these constructions emerge and what their outcomes might be. Sarah White's work draws on participant experiences from countries in Africa, Asia and Latin America. This shift in the focus of wellbeing scholarship has produced a rich output of contextual and constructivist findings that have disrupted the conventional and standardising approaches, and it has critiqued the lens from the Global North that has been the primary analytic frame for wellbeing scholarship.

The relational and collective analyses of wellbeing that White (2016), Atkinson (2013) and Atkinson et al. (2012) deliberated are closer to the wellbeing approach that I use in this chapter. White outlined the subjective, material and relational dimensions of wellbeing and further suggested viewing it as a process, paying attention to 'life-course' and incorporating 'reflections on the past and expectations of the future' (White 2016, p. 10). 
I argue that for young women like Mele, Ema and Amelia, wellbeing is a relational activity that is shaped and experienced through their interactions with communities, institutions and structures. The spatial and temporal dimensions of wellbeing allow us to understand the connections between the transnational histories of the young women, their complex identities as young women in densely urban settings in Melbourne, their access to social, educational and employment resources and their future aspirations. By highlighting the relational, spatial and temporal dimensions of wellbeing as the units of analysis, the historical, social, economic and political processes that contribute to wellbeing experiences are made visible. Finally, I argue that wellbeing needs to be conceptualised as an ongoing set of social practices, as open-ended rather than fixed, to identify where and how these structural forces stymie young women's pathways to wellbeing. Medical anthropologist, Sarah Willen, similarly argued against abstract and definitional concepts using the notion of dignity as an example. She proposes that 'dignity' needs to be studied as a process: 'The notion of dignity becomes ethnographically visible, and anthropologically meaningful, only in motion: as dignity harmed, denied, violated, or stripped away_or, conversely, as dignity pursued, safeguarded, recuperated, reclaimed' (Willen 2014).

Similarly, I suggest it is through viewing wellbeing as an ongoing set of practices and relationships that we identify its nuances, those factors that act as barriers to wellbeing, and that we identify where and how wellbeing experiences are disrupted. It is in recognising wellbeing as a process that the structural implications of regulatory regimes become visible. In the following section, I focus on the effect of these regulatory changes in the lives of young Pasifika women like Ema, Amelia and Mele.

\section{Stories From the Field}

I'd like to study, but I need money; there's no future for it. It's like for now, when I was in Auckland, I was gonna go study, but then we moved here, it's just changed. (Ema)

When I first met Ema in 2015, she had just finished school without sitting for her final examinations (on the advice of her teachers) and she was unclear about her future prospects. She was unable to return to Aotearoa to pursue her studies because she did not have the financial resources to support herself. She had dreamed of doing theatre studies in Aotearoa 
before her family moved to Melbourne. Early in 2016, I learned that she was enrolled in a short-term course on leadership through a registered private education provider, with a promise of employment at the end of the course. It seemed a strange choice for a young woman just out of high school—more so that a reserved young woman would be matched to a leadership course as an employment pathway. Ema's experience is not unusual. Deregulation in the education 'industry' created opportunities for private organisations to access government funding, by delivering short-course training that generally took the form of qualifications with low overhead costs for groups who were not well informed about postsecondary education choices. Some training businesses pursued aggressive marketing to sign up individuals to their courses by targeting young people such as Ema in disadvantaged communities, whose information about the educational quality of the courses was limited. The leadership work did not eventuate for Ema at the end of the course. Through her friendship networks, she picked up some shifts at a fast-food outlet. At this point, her attendance at Pasifika Voices became more and more infrequent. After several months of not seeing her, I heard through the other young women that Ema had picked up more shifts at her workplace. 'I don't have many talents, I'm lost', was how she described herself when I first spoke at length with her after she had finished school.

The economic circumstances of Ema's family were precarious. She was one of seven siblings, and her father and older siblings all worked in lowskilled roles. Ema's short leadership course was futile in terms of qualifying her for a good starting point. It gave her no pathway that would advance her beyond the type of job she was doing in the low-skilled segment of the labour market.

Ema's education and employment pathways illustrate the multiple ways in which her life chances and wellbeing are shaped and compromised by structural forces. Constraints on Ema's wellbeing are inherent in her position (Quesada et al. 2011) as an unprotected temporary resident; as a young woman who completed high school without tertiary entry qualifications; as a member of a large family who relies financially on a combined household income; as someone unable to access welfare services and support in Australia; and as a young woman without extensive family networks in Australia. All these elements of Ema's life and their collective effect on her wellbeing may not be immediately evident. The structural constraints on Ema's wellbeing arise from the interconnections and relationality between the immigration policies and the economic 
contexts in which she and her family were embedded. Ema's position in the social hierarchy-with its political, economic and social networks of power relationships (Bourgois et al. 2017)—created a structural vulnerability that limited her wellbeing potential.

Mele's and Amelia's plans for further study were also shaped by the post2001 regulations. Mele finished high school in 2016. Her family had moved to Australia when she was eight, which left her not quite qualified for the 10-year residence requirement to access financial assistance for university in Australia. While waiting for the 10-year qualification, she returned to Aotearoa to stay with family and to work and build up her savings. Amelia's family had arrived more recently-in 2015. Like Ema, Amelia's priorities after completing high school were to find work, and she was unable to finance her post-secondary studies. When I met Amelia in early 2017, she was taking a year off so she could work in retail to save money to fund her studies. She was saving up to go to Queensland, where she could stay with relatives and pursue her studies. Though she seriously considered it, she was unable to apply to join the police academy in Melbourne due to her temporary visa status. After navigating the Victoria Police website myself, I was left with a sense of ambiguity about Amelia's eligibility. According to the force's prerequisites for application, SCV holders are eligible, but it is less clear whether non-protected visa holders are.

While Mele qualified for tertiary fee assistance after a wait of 12 months, Ema and Amelia would have to wait until they were well into their 20s before they could access student financial support. Though their families worked and paid taxes in Australia, this marker of citizenship was insufficient to entitle their children access to higher education and training opportunities. For many of the young women, these restrictions to accessing the system of deferred loan finance that the Australian government provided to most qualified school leavers was a common problem. The concept of structural vulnerability shows how the administrative regulation of citizenship benefits profoundly shapes the opportunities for these young women. Ultimately, their vulnerability is based on their location in the 'multiple overlapping and mutually reinforcing power hierarchies' and 'policy level statuses' (Bourgois et al. 2017, p. 300).

Data from recent studies shows that participation in higher education is much lower for young Pasifika with SCV visas when compared to those with permanent resident or Australian citizenship status (Kearney 2012; 
Kearney \& Glen 2017). This low level of participation is exacerbated by the 10 -year wait to qualify for support. These exclusionary processes come at a high cost for Pasifika youth and their families, as well as for the nation and its investment in its youth. As Judith Kearney and Matthew Glen (2017, p. 10) highlighted, the lower levels of higher education participation also have implications for the levels of 'school engagement and educational aspirations of their younger siblings'. A youth worker I spoke with confirmed this, saying that 'for young Pasifika, it is hard to stay engaged knowing there's nothing at the end of high school'. The Australian government's stated position on education is that 'education is fundamental to achieving a fairer and stronger Australia and for many provides a pathway out of disadvantage' (Commonwealth of Australia 2009, p. 9). The implied intention in this official statement is clearly inconsistent with the exclusionary processes that limit the access of many New Zealand citizens settled in Australia to higher education.

Barriers to wellbeing are embedded and interconnected in the socioeconomic hierarchies that structure the everyday lives of young Pasifika. The structural vulnerability of households can escalate rapidly under these immigration regulations. This became strongly evident to me at an information forum for Pasifika who were affected by the 2001 immigration changes. This advocacy event was the initiative of a group of Pasifika women who had participated in a project called 'Our Community, Our Rights', which was organised by a health organisation in Melbourne's west. There was a sizeable turnout for the evening event. During the evening, a young Pasifika woman whose family had moved from Aotearoa for 'a better life' recounted an anecdote that resonated with the audience. She had completed her post-secondary qualifications in early childhood studies through the state government's vocational training system. Because she could not support herself while looking for work in the early childhood sector (and she was ineligible for welfare benefits), she fell back to irregular work in retail and hospitality. She and her family had moved their household between states and cities multiple times in search of stable employment. Matters were further complicated for the family when her brother, who had spent all his adult life in Australia, was deported by the Australian authorities to Aotearoa.

Due to changes to the Migration Amendment Act 2014, the state has the power to deport temporary residents (including non-protected SCV New Zealand citizens) who are deemed to be 'of bad character' or who have served a prison sentence of 12 months in Australia (Mares 2016, 
pp. 146-147). These temporary residents have their visas cancelled automatically, and a visa cancellation on these grounds prevents deportees from returning to Australia. For many families like this young Pasifika woman's, deportations separate families and result in young people returning to countries, in this case Aotearoa, where they have no immediate family support networks or where they have not lived as young adults.

The threat of deportation (with its implications of prolonged detention), separation from family and the uncertainty of starting again in Aotearoa weigh on the Pasifika communities, in which there are close networks among non-protected SCV visa holders. Hoeskstra's (2016, p. 4) work with undocumented migrants in the United States illustrates how deportation threats in themselves enable a hostile environment by provoking 'physical and psychological vulnerability' as much as the actual act of being deported. For the young woman who spoke that evening, the climate created within her community by the draconian application of immigration regulations is one of multiple structural factors (e.g. economic precarity, housing instability and lack of legal redress) undermining her wellbeing.

There were many more stories that evening of families who were unable to access services and support because of their unprotected temporary visa status. A single parent with three school-aged children worried about her children's ineligibility for tertiary assistance. Another parent could not access carer's allowance to take care of a sick daughter. The full implications of their precarious positionality become abundantly clear to families when they need access to financial assistance or support due to 'the vagaries of existence'-serious illness, retrenchment, work accidents and relationship breakdowns (Mares 2016, p. 178). Finally, in case of unexpected hardships and change of circumstances, they are denied access to services that are available to the majority of Australian residents through the social safety net.

The links between wellbeing and immigration status have not been as extensively theorised in Australia as they have in the United States. There are many opportunities for research in this area due to the increasingly higher numbers of temporary residents and the mounting evidence for a portion of the population who is stuck in the segmented layers of the labour force. There are complex patterns resulting from various layers of immigration status and the implications that these have for accessing health care. Scholars in the United States (Cartwright 2011; Heidbrink 2014; Holmes 2011) have ethnographically documented the effects of 
these immigration status issues on the wellbeing of participants. Recent scholarship by Helen Lee and Makiko Nishitani (2018) takes a step towards addressing this research gap in relation to Pasifika in Australia. Their ethnographic study analyses the complex relationships between the labour market segmentation, economic precarity, residency status and intergenerational disadvantage that is experienced by Pasifika in the Australian agricultural sector. Parallel studies of Pasifika and other communities on perilous temporary visas in Australian cities would be invaluable.

The structural vulnerability concept that was proposed by Quesada et al. (2011) unmasks the connections between the political and economic restrictions of the unprotected SCVs and their effect on the lives of many young Pasifika and their families. These political restrictions further perpetuate stereotypical depictions of Pasifika communities in low-skilled and economically precarious roles that many of the young women in this study referred to. Peter Mares (2016) in his book, Not Quite Australia, argued that a large percentage of people who are affected by the 2001 regulations are Maori and Pasifika. For many in the segmented labour market, the complicated and costly steps that are involved in transitioning to permanent residency are out of reach. This leaves young women like Ema and Amelia and their families in an ongoing state of impermanence, with little opportunity to transition out of their low-skilled roles.

The application of the structural vulnerability framework in a political context in which increasingly nativist and fortified immigration policies interlock with cuts to welfare and social services support, while governments benefit from taxation revenue collected from temporary visa holders, is particularly pertinent. For young women like Ema and Amelia, these restrictions result in the transforming of what were initially temporary low-skilled roles into permanent and long-term ones as a way protecting them and supporting their families.

Apart from the disadvantages that are posed by a lack of access to education and welfare support, the post-2001 changes raise larger concerns of wellbeing that are connected to young people's sense of belonging and citizenship. A key result of the changes is the creation of a multi-tiered system that is composed of protected SCV holders, non-protected SCV holders and Australian citizens, and the differences in their entitlements and restrictions. 
In the next section, I analyse contemporary dominant and oftencontradictory discourses of participation and belonging-discourses that belie the realities for Pasifika youth with non-protected SCV visas. At one point during my fieldwork, I accompanied three of the young Pasifika women and an Acacia council representative to a meeting with federal parliamentarians who constituted the Joint Standing Committee on Migration. As part of their inquiry into migrant settlement outcomes, this group was meeting with representatives from community organisations and individuals in Melbourne. It became apparent in the hearing that the parliamentarians had little interest in investigating the structural issues that some of the young Pasifika women and their families face, resulting from their unprotected temporary visa status.

\section{Structural Wellbeing}

Our interaction with the politicians exemplified how mainstream politics and dominant discourses of belonging and participation mesh together, as well as identified the (deliberate) discursive misunderstanding of the effects of regulatory barriers on young people's everyday lives. When I read the entire script of the sessions that the committee had with various representatives on the day we met them, there was a disproportionate focus from the chair of the committee on the 'antisocial' behaviour of migrant youth, visa cancellations for youth who were engaged in 'criminal' activities and the offending patterns of young people from specific cultural communities. His evidence base for his comments appeared to be a tabloid newspaper in Melbourne that reported regularly on the 'crimes' that were committed by 'migrant gangs'. For the political representatives, there appeared to be little perception or empathy that would lead to an acknowledgement of the young people's concerns regarding school and their references to stereotyping, labelling and racial profiling as examples of negative settlement experiences. For a committee whose brief was to consider the settlement experiences of second-generation migrants, it seemed fair to assume that these concerns and those for the educational and economic participation of migrant youth would be of interest. The 2001 changes have deep implications for family and community concepts of belonging and wellbeing, and they leave a sense of ambivalence about citizenship rights (McMillan 2017). 
One of the politicians referred to Harmony Day (recognised elsewhere in the world as the International Day for the Elimination of Racial Discrimination) as an example of an event that Pasifika youth could participate in. Harmony Day is held on 21 March every year to celebrate Australia's 'success' as a culturally diverse country, and schools and workplaces commemorate the day by holding culinary and cultural events. The focus on cultural explanations (Viruell-Fuentes et al. 2012; Youdell 2012), such as participation in 'multicultural' events, can operate to gloss over the key structural obstacle that immigration status poses for the young Pasifika who are affected by changes to visa rules; by design, these exclude them from eligibility for various welfare services and educational opportunities. Political processes such as the parliamentary committee's hearings in the public sphere do not serve to inform about as much as to obscure the powerful ways in which power and structural privilege thwart young people's wellbeing experiences and discourage their sense of belonging. Lack of access to education, welfare and employment support adds layers of difficulty to communities who are already disadvantaged in many ways. It diminishes the potential of Pasifika youth to secure their wellbeing; it sustains and inflicts disadvantages that are transmitted between generations.

Medical anthropologist Elizabeth Cartwright suggested that the immigration system in the United States is a powerful pathogen' for immigrants from Mexico, through the conditions created by the different immigration categories (Cartwright 2011, p. 475). The 2001 amendments to the Australian social security laws provide a glimpse into the numerous ways in which young women like Ema and Amelia, their siblings and family members are separated from the categories of Australian citizenship and permanent residence and its entitlements. The 'fractured terrain of belonging' that contributes negatively to wellbeing (Cartwright 2011, p. 481) was evident in such stories as the brother, who had been deported despite living his life in Australia; Ema, who was unable to pursue her dream of theatre studies because she needed to earn an income; and Mele and Amelia, who have had to defer their studies. There are numerous other examples of young Pasifika and their families who are constrained by a lack of access to educational and welfare support and by the ever-constant threat of visa cancellation. Yet, for many of the young women who I met, there was no talk of their families returning to Aotearoa in the immediate future. They had warm memories of neighbourhoods, family and friends in Aotearoa, but they and their families planned to 
live and work in Australia. This clearly demonstrates their commitment and responsibility, which discourse in the public sphere represents as the requirement of the nation state. But, unlike most citizens, Pasifika youth with unprotected visas are confronted with additional structural hurdles that pose significant immediate and long-term consequences not just for their futures, but also for the overall wellbeing of the communities to which they belong.

\section{Conclusion}

In this chapter, I have drawn on my ethnographic engagement with young Pasifika women from Aotearoa/New Zealand who moved to Australia with their families after 2001 to illustrate the effect of regulatory regimes on their wellbeing. Using the concept of structural vulnerability, I show how restricted access to economic and educational resources as a result of the regulatory changes shape the wellbeing futures of Pasifika youth. There is currently a sizeable group of young Pasifika in Australia whose futures are determined by these regulatory restrictions and who will grow up without accessing the benefits and rights that young Australian citizens and permanent residents have.

These restrictions raise critical questions about the commitment and the responsibility of the state in taking care of 'its family' while expecting young people to show commitment towards the country that they are living in. The Pasifika population in Australia is a youthful one (Ravulo 2015) and, therefore, government policies on unprotected temporary residents determine life courses from an early age and have far-reaching effects on the life opportunities and potential of young Pasifika.

Maori scholar Linda Tuhiwai Smith (2013, p. 228) stated:

The future, in one sense, is now. It's not an abstract, theoretical or even visionary picture of what the world may be like in fifty or a hundred years. It is, rather, the potential we hold now, as a society.

To address the wellbeing futures of Pasifika youth who arrived in Australia after 2001, we need to acknowledge the effect of these restrictions on their access to social and economic resources right now. 


\section{Acknowledgements}

I would like to express my thanks to all the young women from Pasifika Voices who generously invited me to participate in their projects between September 2015 and April 2017, and who shared their stories. My thanks also to the staff at the Acacia council's youth services unit and to the many people from the Pasifika communities who took an interest in this project and made time to share their reflections.

Thank you to Professor Helen Lee, who encouraged me to present my preliminary findings at the Association for Social Anthropology in Oceania meeting in New Orleans in February 2018. Thanks also to Cathy Vaughan, Kalissa Alexeyeff and Richard Chenhall from the University of Melbourne.

This study was undertaken as part of my $\mathrm{PhD}$ research, through the Centre for Health Equity, School of Population and Global Health at the University of Melbourne. I am grateful for the Australian Government Research Training Program Stipend Scholarship that funded this study.

\section{References}

Atkinson, S 2013, 'Beyond components of wellbeing: The effects of relational and situated assemblage', Topoi, vol. 32, pp. 137-144, doi.org/10.1007/ s11245-013-9164-0

Atkinson, S, Fuller, S \& Painter, J 2012, 'Wellbeing and place', in S Atkinson, S Fuller \& J Painter (eds), Wellbeing and Place, Ashgate Publishing Limited, Farnham, pp. 1-14.

Bourgois, P, Holmes, SM, Sue, K \& Quesada, J 2017, 'Structural vulnerability: Operationalizing the concept to address health disparities in clinical care', Academic Medicine, vol. 92, no. 3, pp. 299-307, doi.org/10.1097/ACM. 0000000000001294

Cartwright, E 2011, 'Immigrant dreams: Legal pathologies and structural vulnerabilities along the immigration continuum', Medical Anthropology: Cross-Cultural Studies in Health and Illness, vol. 30, no. 5, pp. 475-495, doi.org/10.1080/01459740.2011.577044 
Commonwealth of Australia 2009, A stronger fairer Australia, viewed 5 November 2018, (site discontinued), www.socialinclusion.gov.au/Resources/Documents/ ReportAStongerFairerAustralia.pdf

Farmer, P 2003, Pathologies of power health, human rights and the new war on the poor, University of California Press, Berkeley and Los Angeles.

Hamer, P 2014, "Sophisticated and unsuited", Australian barriers to Pacific Islander migration from New Zealand', Political Science, vol. 66, no. 2, pp. 93-118, doi.org/10.1177/0032318714554495

Heidbrink, L 2014, Migrant youth, transnational families, and the state: Care and contested interests, University of Pennsylvania Press, Philadelphia.

Hoeskstra, E 2016, 'Bodies of resistance: The migrant health justice movement and claims of biocitizenship', paper presented at American Sociological Association Annual Meeting, Seattle, 20-23 August.

Holmes, SM 2011, 'Structural vulnerability and hierarchies of ethnicity and citizenship on the farm', Medical Anthropology: Cross Cultural Studies in Health and Illness, vol. 30, no. 4, pp. 425-449, doi.org/10.1080/01459740. 2011.576728

Kearney, J 2012, 'Unlucky in a lucky country: A commentary on policies and practices that restrict access to higher education in Australia', Journal of Social Inclusion, vol. 3, no. 1, pp. 130-134.

Kearney, J \& Glen, M 2017, 'The effects of citizenship and ethnicity on the education pathways of Pacific youth in Australia', Education, Citizenship and Social Justice, vol. 12, no. 3, pp. 1-13, doi.org/10.1177/1746197916684644

Lee, H \& Nishitani, M 2018, Who are the Pacific farmworkers in Australia?, DEVPOLICYBLOG, blog post, 6 March, viewed 30 August 2018, www.dev policy.org/pacific-farmworkers-in-australia-20180206

Mares, P 2016, Not quite Australian: How temporary migration is changing the nation, Text Publishing, Melbourne.

McCarthy, A, Shaban, R \& Stone, C 2010, 'Fa'afaletui: A framework for the promotion of renal health in an Australian Samoan community', Journal of Transcultural Nursing, vol. 22, no. 1, pp. 55-62, doi.org/10.1177/ 1043659610387154

McGowan, M 2017, 'Warm relations as Turnbull and Arden stow differences in chilly bin', The Guardian, 5 November, viewed 3 December 2018 (story removed), www.theguardian.com/Australia-news/2017/nov/05/warmrelations-as-turnbull-and-arden-stow-differences-in-chilly-bin 
McMillan, K 2017, “'Affective integration” and access to the rights of permanent residency: New Zealanders resident in Australia post-2001', Ethnicities, vol. 17, no. 1, pp. 103-127, doi.org/10.1177/1468796816656675

Quesada, J, Hart, LK \& Bourgois, P 2011, 'Structural vulnerability and health: Latino migrant laborers in the United States', Medical Anthropology, vol. 30, no. 4, pp. 339-362, doi.org/10.1080/01459740.2011.576725

Ravulo, J 2015, Pacific Communities in Australia, University of Western Sydney, viewed 5 October 2015 (page removed), www.uws.edu.au/_data/assest/pdf_ file/0006/923361/SSP5680_Pacific_Communities_in_Aust_FA_LR.pdf

Rodriguez, L 2013, 'The subjective experience of Polynesians in the Australian health system', Health Sociology Review, vol. 22, no. 4, pp. 411-421.

Rodriguez, L \& George, JR 2014, 'Is genetic labeling of "risk" related to obesity contributing to resistance and fatalism in Polynesian communities?', The Contemporary Pacific, vol. 26, no. 1, pp. 65-93, doi.org/10.1353/ cp.2014.0005

Social Security Act 1991, Federal Register of Legislation, Australian Government, viewed 5 November 2018, www.legislation.gov.au/Series/C2004A04121

Tuhiwai Smith, L 2013, 'The future is now', in M Rashbrooke (ed.), Inequality: A New Zealand crisis, Bridget William Books, Wellington, pp. 228-235.

Viruell-Fuentes, EA, Miranda, PY \& Abdulrahim, S 2012, 'More than culture: Structural racism, intersectionality theory and immigrant health', Social Science \& Medicine, vol. 75, pp. 2099-2106, doi.org/10.1016/j.socscimed. 2011.12.037

Walsh, T 2015, 'New Zealanders in crisis in Australia: The absence of a social safety net', New Zealand Universities Law Review, vol. 26, no. 3, pp. 673-702.

White, SC 2016, 'Introduction: The many faces of wellbeing', in SC White \& C Blackmore (eds), Cultures of wellbeing: Method, place, policy, Palgrave Macmillan, Basingstoke, pp. 1-44.

Willen, SS 2014, Top of the Heap, Somastosphere, blog post, 12 September, viewed 28 June 2018, somatosphere.net/2014/top-of-the-heap-sarah-willen. html/

Youdell, D 2012, 'Fabricating "Pacific Islander": Pedagogies of expropriation, return and resistance and other lessons from a "Multicultural Day", Race Ethnicity and Education, vol. 15, no. 2, pp. 141-155, doi.org/10.1080/1361 3324.2011 .569243 
This text is taken from Pacific Youth: Local and Global Futures, edited by Helen Lee, published 2019 by ANU Press, The Australian National University, Canberra, Australia.

doi.org/10.22459/PY.2019.12 